Nirali N. Lohiya, Neha A. Kajale, Nikhil N. Lohiya, Vaman V. Khadilkar, Ketan Gondhalekar and Anuradha Khadilkar*

\title{
Diabetes distress in Indian children with type 1 diabetes mellitus and their mothers
}

https://doi.org/10.1515/jpem-2020-0339

Received June 8, 2020; accepted September 26, 2020;

published online November 13, 2020

\section{Abstract}

Background: Children and their mothers, who are usually the primary caregivers, are likely to be distressed due to type 1 diabetes (T1DM).

Objectives: (1) To assess diabetes-specific distress (DD) perceived by children and adolescents with T1DM and their mothers and association of distress between children and mothers. (2) To study the association of diabetes distress with glycemic control and disease duration.

Subjects: Children and adolescents with T1DM over eight years and their mothers.

Methods: Clinical data were recorded. DD was assessed by Problem Associated in Diabetes-Pediatric (PAID-Peds) (range 0-80) and Problem Associated in Diabetes-Parents Revised (PAID-PR) (range 0-72) questionnaires (higher scores indicate higher distress); administered to children and mothers, respectively. Sub-dimensions in questionnaires included diabetes-related emotional problems, and treatment-, food-, and social support-related problems. Correlation analysis (Spearman's) was performed, and a paired $t$-test was used to compare PAID-Peds and PAID-PR (SPSS 25).

Results: Mean PAID-Peds and PAID-PR scores in 67 children and mothers were $24.4 \pm 18.1$ and $31.9 \pm 21.5$, respectively ( $\mathrm{p}=0.009)$, and a significant correlation was noted between their scores $(\mathrm{R}=0.45, \mathrm{p}=0.001)$. PAID-Peds score was positively associated with $\mathrm{HbA1c}(\mathrm{R}=0.25, \mathrm{p}=0.04)$. Diabetes-related emotional problems of mothers and

*Corresponding author: Dr. Anuradha Khadilkar, MD (Pediatrics), Growth and Pediatric Endocrine, Hirabai Cowasji Jehangir Medical Research Institute, Jehangir Hospital, 32 Sassoon Road, Pune 411 001, Maharashtra, India, Phone: +91 20 26141340, Fax: +91 2026141340 , E-mail: anuradhavkhadilkar@gmail.com

Nirali N. Lohiya, Developmental and Behavioural Pediatrics, Dr. D. Y. Patil Medical College Hospital and Research Centre, Pune, Maharashtra, India

Neha A. Kajale, Nikhil N. Lohiya, Vaman V. Khadilkar and Ketan Gondhalekar, Growth and Pediatric Endocrine, Hirabai Cowasji Jehangir Medical Research Institute, Pune, Maharashtra, India children ( $\mathrm{R}=0.38, \mathrm{p}=0.003)$, treatment problems $(\mathrm{R}=0.5$, $\mathrm{p}=0.001)$, and food problems $(\mathrm{R}=0.24, \mathrm{p}=0.05)$ correlated positively. Subdimension scores were significantly different in children and mothers except in the social support domain.

Conclusion: DD was higher in mothers than children; higher distress in children was associated with poor metabolic control. Evaluation of DD needs to be performed in children with T1DM.

Keywords: children; diabetes distress; India; mother; type 1 diabetes.

\section{Introduction}

According to the International Diabetes Federation 2015 report, India has the second-largest population of children living with type 1 diabetes mellitus (T1DM) [1]. The average prevalence of T1DM in India is believed to be 10.2 cases/ 100,000 children [2]. T1DM is a chronic disorder, where, not only the affected individuals, but also their families are involved in daily care of the child [3]. Diabetes care in children aims to provide a good quality of life and optimal metabolic control so as to minimize complications.

The recommended treatment regimens for T1DM are quite complex and challenging and require monitoring of blood glucose concentrations and carbohydrate intake, insulin administration and modifying insulin doses to match diet and activity patterns [4]. Compliance with such intensive treatment is likely to be stressful and result in distress for children and adolescents with T1DM as well as for their caregivers [5].

Distress specific to diabetes ("diabetes-specific distress") is defined as negative emotional responses to the diagnosis or burden of diabetes, or "worries, problems, and fears" $[6,7]$. Reports suggest that mothers of children with T1DM have elevated stress due to the management of their child's illness [8]. Also, during adolescence, developing autonomy and new peer relationships result in conflict with parents in relation to diabetes care [9]. Treatment compliance and parental monitoring for diabetes management thus declines [10, 11]. This is especially worrisome as adolescents with T1DM commonly face high levels of diabetes-specific distress (DD) [12-14]. 
Parental stress is believed to result from daily diabetesrelated tasks, financial problems, managing blood glucose fluctuations, and very often, guilt and fear of future medical complications $[15,16]$. If parents feel distressed or overburdened, they may prematurely transfer the responsibility of diabetes management to their child, leading to poor control. Thus, the parental burden is an important construct for Assessment and intervention in children and adolescents with diabetes [16, 17]; further, DD in parents has been shown to impact patient health outcomes [18-21].

DD may be assessed using a questionnaire-based tool known as Problem Areas in Diabetes Survey (PAID) [3], which was first created and validated in the 1990s to measure and assess diabetes-related burden in adults with diabetes. Different applications of the PAID have been created and validated for use in the pediatric population; the PAID-Parent Revised survey (PAID-PR) [22] assesses diabetes-related burden in parents, while, the Pediatric PAID (PAID-Peds) is a companion to the PAID-PR for use in younger patients as well as teens, spanning the age group of $8-17$ years [23].

The ISPAD Consensus Guideline since 2000 [24] states that "Psychosocial factors are the most important influences affecting the care and management of diabetes", making it imperative to assess Diabetes Distress in children and adolescents as well as their parents for improved management of T1DM. Very little research has been conducted to evaluate psychosocial distress in Indian children and adolescents with T1DM and their parents.

Therefore, the aims of our study were (1) to assess diabetes-specific distress perceived by children and adolescents with T1DM and their mothers and to study association of diabetes distress between children and mothers. (2) To study the association of diabetes distress with glycemic control and disease duration.

\section{Methods}

\section{Participants}

The study was conducted at a tertiary level care hospital, at Pune (Western India). The pediatric endocrine unit runs a multidisciplinary clinic for children and adolescents with T1DM (the "Sweetlings" project). The clinic supports medical needs (insulin, glucometers, strips for testing, other medications, and medical consultations) of children with diabetes from lower and middle socioeconomic classes. All children and adolescents over eight years of age who were on basal-bolus regimen (and their mothers) attending the clinic were offered the study. Of 110 dyads, 78 agreed to participate in the study. Inclusion criteria were children diagnosed with T1DM with age between 8 and 17 years [25] and disease duration of more than one year who were on basal-bolus regimen (so as to have a uniform insulin regimen). Children under eight years (as they would not be able to answer questions), those with associated comorbidities including celiac disease, associated syndromes, intellectual disability, polyendocrinopathy, and diabetes associated with chronic pancreatitis were excluded.

Written informed consent and assent were obtained from participating mothers and children, respectively, after explaining the study protocol. The institutional ethics committee approved the study before it was started. The study period was from November 2018 to March 2019.

\section{Demographic information}

Data were obtained from the participants using validated questionnaires on socioeconomic class [26], parent and child education, disease duration, diabetic ketoacidosis (DKA) episodes in the past one year, hypoglycemic episodes in the past month and insulin dosage. Daily insulin requirements were calculated as IU per kilogram per day.

\section{Anthropometry and glycemic control}

Height and weight of children were measured using standard protocols (Seca Portable stadiometer, 20-205 cm, Hamburg Germany and SECA digital weighing 876 Flat scale, Seca Gmbh \& Co., Hamburg, Germany). BMI was computed using the formula weight $(\mathrm{kg}) / \mathrm{height}$ $\left(\mathrm{m}^{2}\right)$. Age and gender-matched $Z$ scores for height, weight, and BMI were calculated using ethnic-specific data [27]. For assessing glycemic control, HbA1c was tested using the HPLC method (reference range 4-5.6\%).

\section{PAID Scale and post-classification in subdimensions}

PAID-Peds questionnaire with 20 questions, which assesses the burden over the past one month, was administered to the 8-17 year old children/adolescents [25]. The 18 items PAID-PR was administered to the mother of the child with T1DM to assess the perceived burden associated with diabetes care of her child [28]. The items in both the questionnaires were answered on a 5-point Likert type scale $0-4$ $(0=$ not a problem, $1=$ minor problem, $2=$ moderate problem, 3 = somewhat serious problem, $4=$ serious problem) increasing score on the Likert scale denotes increasing burden perceived related to diabetes [29]. The total scores range from 0 to 80 in PAID-Peds and 0 to 72 in PAID-PR, respectively. A somewhat serious/serious problem was defined when the problem score was 3 or more. The items in both PAID-Peds and PAID-PR were grouped into four subdimensionsdiabetes-related emotional problems, treatment-related problems, food-related problems, and social support-related problems [30]. Using depression measures to screen for diabetes-specific emotional distress resulted in poor to modest screening performance. If we assume that screening employing multiple questionnaires is difficult because of time and resource constraints in clinical practice, the PAID questionnaire could be used for the Assessment of emotional distress related to diabetes as well as for screening for depression in diabetes. Hence, PAID-Peds and PAID-PR were used for Assessment in children with T1DM and their mothers [31]. The questionnaires were translated into the local language (Marathi) with the help of a translator and back-translated in English before use. Since the total number of questions were different in PAID-Peds and PAID-PR, while comparing 
these two scores the denominator was made uniform (80) in both. Further, the number of problems were different in each subdimension of child and mother, the denominator of each subdimension was also made uniform by using the formula [(obtained score/maximum score) *100]. Intraobserver consistency was evaluated by repeat testing of the questionnaire on 10 children-mother dyads (intraclass correlation coefficient $0.85 ; \mathrm{p}=0.001$ ).

\section{Sample size}

To assess moderate correlation between PAID-Peds and PAID-PR $(\mathrm{r}=0.3)$ at $\alpha=0.05$, power of study $=0.8$, we found sample size of 65 children and mother dyads was sufficient. This sample size was also sufficient to observe correlation of PAID-Peds and PAID-PR with metabolic control of the children (HbA1c) [32].

\section{Statistical analysis}

Analysis was performed using SPSS version 25. Demographic, clinical data and PAID-Peds, PAID-PR, and subdimension scores were expressed as mean and SD. The total and four subdimensions scores of PAID-Peds and PAID-PR were compared using a paired $t$-test. Spearman's correlation analysis was performed among PAID-Peds and PAID-PR with HbA1c, disease duration, frequency of DKA admissions in the past one year and the frequency of hypoglycemia in past one year.

The frequency of answers (\%) on the Likert scale for the PAID-Peds and PAID-PR was estimated in all four subdimensions and plotted as a stacked bar; $p$-value $<0.05$ was considered significant.

\section{Results}

A total of 110 children were on basal-bolus regimen in the age group of 8-18 years. Of these 25 children who had associated disorders (hypothyroidism, polyendocrinopathy, celiac disease, intellectual disability, were syndromic or had associated exocrine pancreatic deficiency), parents of six children were illiterate, data were incomplete on five children, and three children refused to participate in the study. Hence, the final analysis was performed on 67 children (32 males and 35 females) and their mothers. The mean age of the children/adolescents with T1DM was $13.8 \pm 3$ years, and the mean disease duration of the study population was $5.3 \pm 3.7$ years. Children belonged to lower/middle socioeconomic class as per classification by Kuppuswami, and most parents $(85 \%)$ had an education of less than 10 years [26]. Fifty-two percent of the mothers were homemakers, while $48 \%$ worked as maids or as daily wage laborer; there were no single mothers in the study group.

The mean HbA1c of the population at the time of the study was $11.1 \pm 2.3 \%$; mean number of visits to the diabetes clinic was $8 \pm 3$ over the past year. The frequency of DKA episodes was 0.0148 per 100 patient years over the past one year. The incidence of hypoglycemia was 0.384 episodes per 100 patient-years. The profile of children with diabetes is illustrated in Table 1.

\section{PAID-Peds and PAID-PR (total and subdimension score analysis)}

The mean PAID-Peds and PAID-PR scores, mean subdimension scores of diabetes-related emotional problems, treatment-related, food-related, and social support problems in PAID-Peds and PAID-PR are depicted in Table 2. To compare differences in levels of stress perceived by parents and children (to understand the areas which need to be worked on together and those requiring a family-centered approach) comparison between scores of the PAID-Peds and PAID-PR and their subdimensions was made. The score (the denominator was made common to 100) was higher in PAID-PR as compared to PAID-Peds in the subdimensions of diabetes-related emotional problems, treatment-related, and food-related problems ( $\mathrm{p}<0.05$ for all). Scores were

Table 1: Demographic profile of children with type 1 diabetes (mean \pm SD).

\begin{tabular}{lr}
\hline Parameters & Mean \pm SD \\
\hline Age, years & $13.8 \pm 3$ \\
Disease duration, years & $5.3 \pm 3.7$ \\
Height $Z$ score & $-0.7 \pm 1.1$ \\
Weight Z score & $-0.7 \pm 1$ \\
BMI Z score & $-0.5 \pm 0.9$ \\
HbA1c, \% & $11.1 \pm 2.3$ \\
DKA episodes (episodes per 100 & 0.0148 \\
patient-years) & \\
Hypoglycemia episodes (episodes per & 0.384 \\
100 patient-years) & \\
\hline
\end{tabular}

Table 2: Total and subdimension analysis of PAID-Peds and PAID-PR $\left({ }^{\star \star} p<0.01\right)$.

\begin{tabular}{lrrr}
\hline Subdimensions & PAID-Peds & PAID-PR & $\begin{array}{r}\text { Paired } \\
\boldsymbol{t} \text {-test }(\boldsymbol{P})\end{array}$ \\
\hline Total & $24.4 \pm 18.1$ & $31.9 \pm 21.5$ & 0.009 \\
Diabetes related emotional & $12.6 \pm 9.7$ & $13.6 \pm 10.2$ & 0.001 \\
problems & & & \\
Treatment related problems & $1.9 \pm 1.8$ & $2.4 \pm 1.9$ & 0.001 \\
Food related problems & $1.8 \pm 2.4$ & $3.4 \pm 3.3$ & 0.04 \\
$\begin{array}{l}\text { Social support related } \\
\text { problems }\end{array}$ & $2.9 \pm 2.8$ & $3.5 \pm 4$ & 0.06 \\
\hline
\end{tabular}

Since the number of problems were different in each subdimension of child and mother, the denominator of each subdimension was made uniform by using the formula [(obtained score/ maximum score)*100]. 
similar in the social support problem subdimension $(\mathrm{p}=0.06)$.

It was observed that there was a moderate correlation between diabetes-related emotional problems of mothers and children $(\mathrm{R}=0.38, \mathrm{p}=0.003)$. The treatment-related subdimensions of mothers and children had a strong and significant correlation $(\mathrm{R}=0.5, \mathrm{p}=0.001)$. There was a moderate correlation of food-related problems $(R=0.24$, $\mathrm{p}=0.05$ ) and no correlation in social support problems $(\mathrm{R}=0.13, \mathrm{p}=0.06)$ between mothers and children. Also, it was noticed that although the subdimensions were correlated, their scores were significantly different in mothers and children except in the social support subdimension. The scores of various subdimensions are illustrated in Table 2.

\section{Association of PAID-Peds and PAID-PR with parameters of glycemic control}

PAID-Peds score was positively associated with HbA1c $(\mathrm{R}=0.25, \mathrm{p}=0.04)$, whereas a negative association was observed with a frequency of hypoglycemic episodes $(\mathrm{R}=-0.27, \mathrm{p}=0.03)$. Disease duration and frequency of DKA episodes had no significant correlation with PAID-Peds. PAID-PR had no significant correlation with disease duration, HbA1c, frequency of hypoglycemia, or DKA episodes. PAID-Peds and PAID-PR had a moderately significant positive correlation $(\mathrm{R}=0.45, \mathrm{p}=0.001)$ (Table 3$)$.
Spearman's correlation analysis of subdimensions of the PAID-Peds showed positive association of HbA1c with diabetes-related emotional problems $(\mathrm{R}=0.32, \mathrm{p}=0.02)$ and food-related problems $(R=0.29, p=0.014)$. Similarly, the frequency of hypoglycemic episodes was negatively associated with child treatment-related scores $(R=-0.32$, $\mathrm{p}=0.03)$.

\section{Analysis of the frequency of problems in PAID-Peds and PAID-PR subdimensions}

While analyzing the subdimensions, it was observed that higher frequency of a somewhat serious/serious problem (defined as score of 3 or more) was reported in the treatmentrelated subdimension of the child as well as the parent. No or minor problem was mostly observed for the social support subdimension of child and parent (Figure 1).

At least one somewhat serious/serious problem (score of 3 or more) was reported among 56 (83.6\%) children. The most common problems were feeling upset when blood sugars were out of range (58.2\%), feeling discouraged with their diabetes treatment plan (40.3\%) and feeling alone with diabetes (31.4\%). Fifty-seven (85\%) mothers reported at least one somewhat serious/serious problem. The most common problems among mothers were: they felt discouraged with their child's diabetes treatment plan (56.7\%), felt scared when thinking about their child having/living with diabetes (41.8\%), felt angry when they

Table 3: Correlation analysis of PAID-Peds, PAID-PR with subdimensions and parameters of diabetes.

\begin{tabular}{|c|c|c|c|c|c|c|}
\hline Score with range mentioned in bracket & $\begin{array}{l}\text { Disease } \\
\text { duration }\end{array}$ & $\begin{array}{r}\text { HbA1c } \\
(\%)\end{array}$ & $\begin{array}{r}\text { Frequency of } \\
\text { hypoglycemic } \\
\text { episodes }\end{array}$ & $\begin{array}{r}\text { Frequency of DKA } \\
\text { admission }\end{array}$ & $\begin{array}{r}\text { PAID- Peds } \\
\text { score }\end{array}$ & $\begin{array}{r}\text { PAID-PR } \\
\text { score }\end{array}$ \\
\hline PAID-Peds score $(0-80)$ & 0.024 & $0.25^{\star}$ & $-0.27^{\star}$ & 0.07 & 1 & $0.45^{\star \star}$ \\
\hline PAID PR score $(0-72)$ & -0.06 & 0.03 & -0.16 & 0.08 & $0.45^{\star \star}$ & 1 \\
\hline $\begin{array}{l}\text { Child diabetes related emotional prob- } \\
\text { lem }(0-48)\end{array}$ & 0.03 & $0.32^{\star}$ & -0.14 & 0.06 & - & - \\
\hline Child treatment related problems $(0-12)$ & -0.03 & 0.21 & $-0.32^{\star}$ & $0.28^{\star}$ & - & - \\
\hline Child food related problems $(0-12)$ & 0.004 & $0.29^{\star}$ & -0.21 & -0.001 & - & - \\
\hline $\begin{array}{l}\text { Child social support related } \\
\text { problem }(0-8)\end{array}$ & 0.09 & 0.04 & -0.16 & 0.003 & - & - \\
\hline $\begin{array}{l}\text { Parents diabetes related emotional } \\
\text { problem }(0-40)\end{array}$ & -0.06 & -0.004 & -0.07 & 0.11 & - & - \\
\hline Parent treatment related problems $(0-4)$ & -0.09 & -0.03 & -0.26 & 0.11 & - & - \\
\hline Parent Food related problems $(0-12)$ & -0.03 & -0.05 & -0.09 & 0.02 & - & - \\
\hline $\begin{array}{l}\text { Parent social support related } \\
\text { problem }(0-16)\end{array}$ & -0.04 & 0.1 & -0.22 & -0.06 & - & - \\
\hline
\end{tabular}

The values shown is of Spearman's $R,{ }^{*} p<0.05{ }^{*} p<0.01$. Since the number of problems were different in each subdimension for child and mother, the denominator of each subdimension was made uniform by using the formula [(obtained score/maximum score) $\left.{ }^{\star} 100\right]$ and to 80 for total scores. 


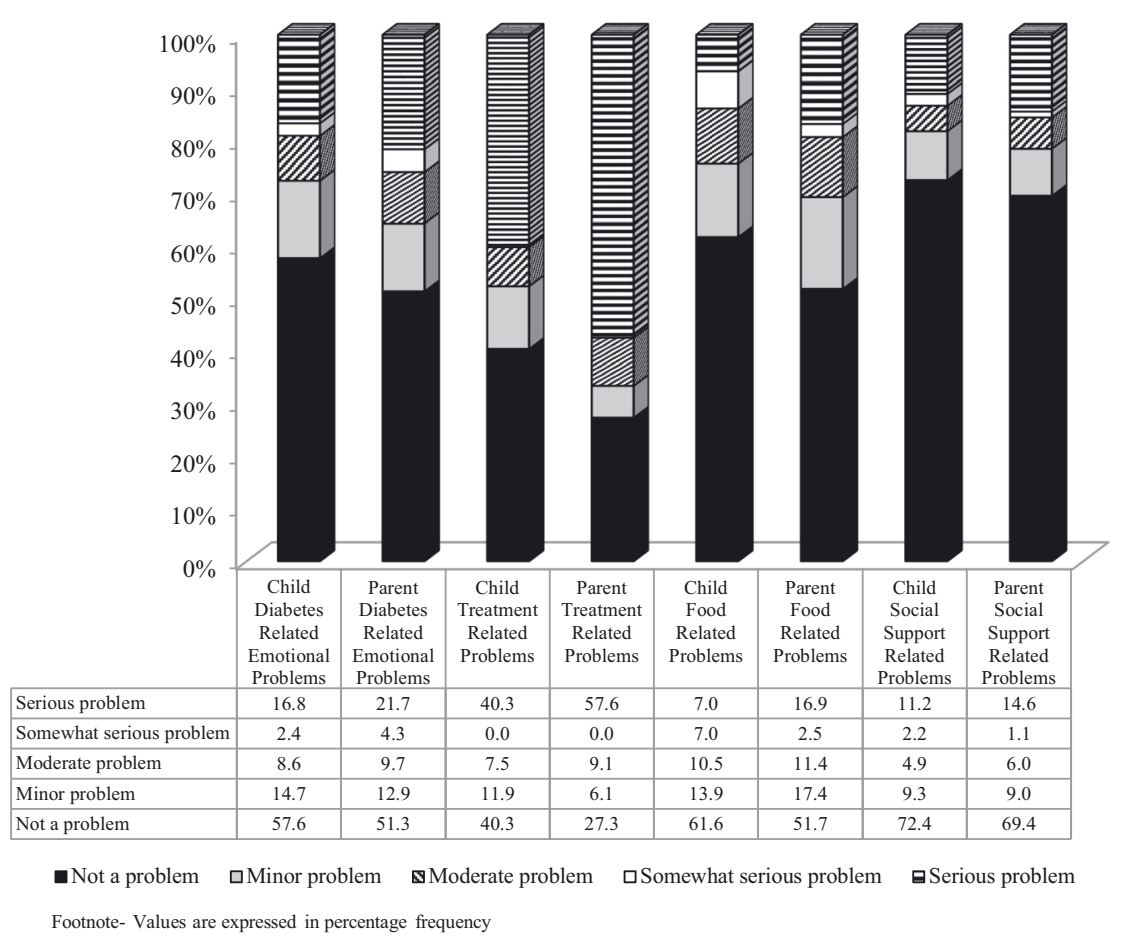

Figure 1: Frequency (\%) on Likert scale in subdimensions of PAID-Peds and PAID-PR. thought about their child having/living with diabetes (29.9\%) and felt "burned out" by the constant effort to manage diabetes (29.9\%) (Supplementary Table).

On the other hand, the items that were perceived as less distressing (scores of 0 or 1 ) by children were-feeling that he/she is excluded from activities or events because of diabetes (98.5\%), feeling that their friends and family are not supportive of diabetes management efforts (82.6\%) and feeling constantly worried about food and eating (82.6\%). Similarly, mothers found less distressing-feeling like she was a "diabetes police" (83.6\%), that other family members were not supportive of managing her child's diabetes (82.1\%) and that her child was excluded from activities/ events because of his/her diabetes (80.6\%) (Supplementary Table).

\section{Discussion}

We observed that the mean diabetes distress score was significantly higher in mothers than in the children/adolescents with diabetes. PAID-Peds had a significant correlation with $\mathrm{HbA1c}$ and frequency of hypoglycemic episodes. HbA1c had a positive relationship with diabetesrelated emotional problem subdimension, whereas the frequency of hypoglycemic episodes had a negative correlation with treatment-related subdimension in the PAID-Peds score. There was a positive correlation of food- related problems, diabetes-related emotional problems, and treatment-related subdimension of mother and child. The maximum frequency of somewhat serious/serious problem was reported in the treatment subdimension of the child as well as the mum.

To the best of our knowledge, ours is the first study from India reporting diabetes distress in children with T1DM and their mothers; we also report data on subdimensions of the PAID scale, which have not been previously reported. Our results of higher diabetes distress in mothers and the relationship of higher distress in children/ adolescents with poor metabolic control have important clinical implications for management of children and adolescents with diabetes. Our study highlights the importance of evaluation for diabetes distress (and its subdimensions) in the management of children/adolescents with diabetes as well as in their mothers.

We observed a significant positive correlation of HbA1c with the PAID-Peds score; this has also been reported by Weissberg-Benchell et al. using the PAID-T scale [24]. However, higher distress was noted in our population as compared to other studies [33]. This possibly was due to differences in HbA1c concentrations which were higher in our population $(8.0 \pm 0.9$ vs. $11.1 \pm 2.3)$. Also, socioeconomic and cultural differences may influence both HbA1c and stress levels [34]. Stress (including diabetic distress) may affect metabolic control (HbA1c) directly through the physiologic changes that occur within the body, e.g. by 
increasing hepatic glycogen production and insulin resistance [35] and indirectly by interfering with an individual's ability to adhere to diabetes regimens $[36,37]$.

Parents have been reported to have significantly higher distress than children as reported by Law et al. [38] and Frazier et al. [32], a finding similar to our study. Proposed reasons for higher stress among parents compared to the child include the fact that parents are more aware of the high level of commitment required for effective management of T1DM [39]. This adds to a parent's individual coping, parenting stress, and efforts to balance family dynamics [40].

A positive correlation of mother's distress with diabetes distress in children is reported in previous studies [ 23 , 32, 38]. The greater perceived burden in the children and parents is associated with increased diabetes-specific family conflict and lower quality of life [23]. On the other hand, higher HbA1c, disagreements about diabetes responsibility among parent and child and parents' perception of reduced adolescent self-efficacy have been reported to predict parental distress [38].

Our subdimension findings are similar to the reports from the adult populations of the Netherlands and the USA, however, no pediatric data were available for comparison [30]. We observed that the treatment-related subdimension had the maximum frequency of serious problem as well as it contributed the highest to diabetes distress in children as well mothers. Treatment of T1DM is complex, additionally, multiple insulin injections at school as well as home, compliance, and support from school teachers, and sick day management may be other contributing factors.

The correlation of diabetes-related emotional problem subdimension with $\mathrm{HbA1c}$ and contribution to the higher scores of PAID-Peds could be explained by negative emotions affecting patients' moods, thoughts, feelings, behavior, and well-being through alterations in circulating glucose levels, which may vary throughout the day. Foodrelated problems in diabetes are an established subdimension contributing to the PAID score [41, 42].

Less distress was observed related to the social support subdimension in both mothers and children, possibly because support groups play an active role in improving complex disorders like diabetes and their outcome [43]. In our multidisciplinary clinics, activities such as support group meetings of children and parents, seminars, and awareness programs about diabetes for newly diagnosed patients, along with their parents, communication skill seminars, and skill enhancement workshops and other activity programs are conducted regularly. Mothers/children and adolescents have an opportunity to interact with counselors at each clinic visit (average eight visits/year, average counseling session at each visit around $30 \mathrm{~min}$ ) and counseling between clinic appointments is provided telephonically. Young adults with T1DM enroll themselves as volunteers in the above program and help in keeping patients and parents connected and motivated through various social media platforms.

Our limitations include that the study is from a single center. We also assessed the group as a whole and could not (due to the modest sample size) investigate the cause for the diabetes distress. We have not assessed the family conflict that may confound diabetes distress; we also did not collect data on whether the families were nuclear or joint. Further, only mothers were assessed as usually mothers are children's primary care givers and accompany children to the clinic. Also, the study group is from a supported clinic where children belonging to middle or lower socioeconomic class are enrolled and the impact of socioeconomic status on distress could not be assessed. Further, children being from the middle or lower socioeconomic class, their glycemic control was poor; our cohort may not be representative of children with diabetes from other Indian centers. Hence, more studies on distress with diabetes from different parts of the country involving various socioeconomic strata are required.

\section{Conclusion}

Diabetes distress in children with T1DM was higher in mothers as compared to children; higher distress in children was associated with poor metabolic control. Evaluation of diabetes distress with subdimensions (such as diabetes-related emotional problems, treatment-related, food-related, and social support problems) and interventions for diabetes-related distress need to be routinely incorporated into management of children with Diabetes Mellitus for holistic family centered interventions rather than a patient centered approach.

Research funding: None declared.

Author contribution: Nirali N. Lohiya: data collection, data analysis, and manuscript drafting; Neha A. Kajale: data analysis and manuscript drafting; Nikhil N. Lohiya: planning and conceptualization of the study, data collection, data analysis, and manuscript drafting; Vaman V. Khadilkar: manuscript drafting; Ketan Gondhalekar: data analysis and manuscript drafting; Anuradha Khadilkar: planning and conceptualization of the study, data collection, data analysis, and manuscript 
drafting. All the authors have accepted responsibility for the entire content of this submitted manuscript and approved submission.

Competing interests: Authors state no conflict of interest.

\section{References}

1. International Diabetes Federation. IDF Diabetes Atlas, 7th ed. Brussels: International Diabetes Federation; 2015.

2. Kalra S, Kalra B, Sharma A. Prevalence of type 1 diabetes mellitus in Karnal district, Haryana state, India. Diabetol Metab Syndr 2010;2:14.

3. Polonsky WH, Anderson BJ, Lohrer PA, Welch G, Jacobson AM, Aponte JE, et al. Assessment of diabetes-related distress. Diabetes Care 1995;18:754-60.

4. DiMeglio LA, Acerini CL, Codner E, Craig ME, Hofer SE, Pillay K, et al. ISPAD Clinical Practice Consensus Guidelines 2018: glycemic control targets and glucose monitoring for children, adolescents, and young adults with diabetes. Pediatr Diabetes 2018;19:105-14.

5. Anderson BJ, Vangsness L, Connell A, Butler D, Goebel-Fabbri A, Laffel LM. Family conflict, adherence, and glycaemic control in youth with short duration type 1 diabetes. Diabet Med 2002;19: 635-42.

6. Fisher L, Gonzalez JS, Polonsky WH. The confusing tale of depression and distress in patients with diabetes: a call for greater clarity and precision. Diabet Med 2014;31:764-72.

7. Gonzalez JS, Fisher L, Polonsky WH. Depression in diabetes: have we been missing something important?. Diabetes Care 2011;34: 236-9.

8. Anderson B, Ho J, Brackett J, Finkelstein D, Laffel L. Parental involvement in diabetes management tasks: relationships to blood glucose monitoring adherence and metabolic control in young adolescents with insulin-dependent diabetes mellitus. J Pediatr 1997;130:257-65.

9. Davidson M, Penney ED, Muller B, Grey M. Stressors and self-care challenges faced by adolescents living with type 1 diabetes. Appl Nurs Res 2004;17:72-80.

10. Main A, Wiebe DJ, Croom AR, Sardone K, Godbey E, Tucker C, et al. Associations of parent-adolescent relationship quality with type 1 diabetes management and depressive symptoms in Latino and Caucasian youth. J Pediatr Psychol 2014;39:1104-14.

11. Miller KM, Foster NC, Beck RW, Bergenstal RM, DuBose SN, DiMeglio LA, et al. Current state of type 1 diabetes treatment in the US: updated data from the T1D Exchange clinic registry. Diabetes Care 2015;38:971-8.

12. Fisher L, Glasgow RE, Mullan JT, Skaff MM, Polonsky WH. Development of a brief diabetes distress screening instrument. Ann Fam Med 2008;6:246-52.

13. Hagger V, Hendrieckx C, Sturt J, Skinner TC, Speight J. Diabetes distress among adolescents with type 1 diabetes: a systematic review. Curr Diabet Rep 2016;16:9.

14. Lašaitè $L$, Ostrauskas $R$, Žalinkevičius R, Jurgevičienè N, Radzevičienè $L$. Diabetes distress in adult type 1 diabetes mellitus men and women with disease onset in childhood and in adulthood. J Diabet Complicat 2016;30:133-7.
15. Moreland EC, Tovar A, Zuehlke JB, Butler DA, Milaszewski K, Laffel $L M$. The impact of physiological, therapeutic and psychosocial variables on glycemic control in youth with type 1 diabetes mellitus. J Pediatr Endocrinol Metab 2004;17:1533-44.

16. Butler DA, Zuehlke JB, Tovar A, Volkening LK, Anderson BJ, Laffel LM. The impact of modifiable family factors on glycemic control among youth with type 1 diabetes. Pediatr Diabetes 2008;9: 373-81.

17. Alan MJ, Hauser ST, Lavori P, Wolfsdorf JI, Herskowitz RD, Milley $\mathrm{JE}$, et al. Adherence among children and adolescents with insulindependent diabetes mellitus over a four-year longitudinal followup: I. The influence of patient coping and adjustment. J Pediatr Psychol 1990;15:511-26.

18. Mackey ER, Struemph K, Powell PW, Chen R, Streisand R, Holmes CS. Maternal depressive symptoms and disease care status in youth with type 1 diabetes. Health Psychol 2014;33:783.

19. Rumburg TM, Lord JH, Savin KL, Jaser SS. Maternal diabetes distress is linked to maternal depressive symptoms and adolescents' glycemic control. Pediatr Diabetes 2017;18:67-70.

20. Streisand R, Mackey ER, Elliot BM, Mednick L, Slaughter IM, Turek J, et al. Parental anxiety and depression associated with caring for a child newly diagnosed with type 1 diabetes: opportunities for education and counseling. Patient EducCouns 2008;73:333-8.

21. Tsiouli E, Alexopoulos EC, Stefanaki C, Darviri C, Chrousos GP. Effects of diabetes-related family stress on glycemic control in young patients with type 1 diabetes: systematic review. Can Fam Phys 2013;59:143-9.

22. Markowitz JT, Volkening LK, Butler DA, Antisdel-Lomaglio J, Anderson BJ, Laffel LM. Re-examining a measure of diabetesrelated burden in parents of young people with Type 1 diabetes: the Problem Areas in Diabetes Survey-Parent Revised version (PAID-PR). Diabet Med 2012;29:526-30.

23. Weissberg-Benchell J, Antisdel-Lomaglio J. Diabetes-specific emotional distress among adolescents: feasibility, reliability, and validity of the problem areas in diabetes-teen version. Pediatr Diabetes 2011;12:341-4.

24. Delamater AM, de Wit M, McDarby V, Malik JA, Hilliard ME, Northam E, et al. ISPAD Clinical Practice Consensus Guidelines 2018: psychological care of children and adolescents with type 1 diabetes. Pediatr Diabetes 2018;19:237-49.

25. Markowitz JT, Volkening LK, Butler DA, Laffel LM. Youth-perceived burden of type 1 diabetes: problem areas in diabetes surveypediatric version (PAID-Peds). J Diabetes Sci Technol 2015;9: 1080-5.

26. Shaikh Z, Pathak R. Revised Kuppuswami and BG Prasad socioeconomic scales for 2016. Int J Commun Med Public Health 2017;4:997-9.

27. Khadilkar V, Yadav S, Agrawal KK, Tamboli S, Banerjee M, Cherian A, et al. Revised IAP growth charts for height, weight and body mass index for 5-to 18-year-old Indian children. Indian Pediatr 2015;52:47-55.

28. Nicolucci A, Kovacs Burns K, Holt RI, Comaschi M, Hermanns N, Ishii $\mathrm{H}$, et al. Diabetes attitudes, wishes and needs second study (DAWN2): cross-national benchmarking of diabetes-related psychosocial outcomes for people with diabetes. Diabet Med 2013;30:767-77.

29. doNascimento Andrade CJ, Alves CD. Influence of socioeconomic and psychological factors in glycemic control in young children with type 1 diabetes mellitus. J Pediatr 2019;95:48-53. 
30. Snoek FJ, Pouwer F, Welch GW, Polonsky WH. Diabetes-related emotional distress in Dutch and US diabetic patients: crosscultural validity of the problem areas in diabetes scale. Diabetes Care 2000;23:1305-9.

31. Hermanns N, Kulzer B, Krichbaum M, Kubiak T, Haak T. How to screen for depression and emotional problems in patients with diabetes: comparison of screening characteristics of depression questionnaires, measurement of diabetes-specific emotional problems and standard clinical Assessment. Diabetologia 2006; 49:469-77.

32. Yi-Frazier JP, Cochrane K, Whitlock K, Rosenberg AR, Pascual M, Beauregard N, et al. Trajectories of acute diabetes-specific stress in adolescents with type 1 diabetes and their caregivers within the first year of diagnosis. J Pediatr Psychol 2018;43: 645-53.

33. Markowitz JT, Volkening LK, Butler DA, Laffel LM. Youth-perceived burden of type 1 diabetes: problem areas in diabetes surveypediatric version (PAID-Peds). J Diabetes Sci Technol 2015;9: 1080-5.

34. Walls ML, Whitbeck LB. Distress among Indigenous North Americans: generalized and culturally relevant stressors. Soc Ment Health 2011;1:124-36.

35. Mortensen HB, Robertson KJ, Aanstoot HJ, Danne T, Holl RW, Hougaard P, et al. Insulin management and metabolic control of type 1 diabetes mellitus in childhood and adolescence in 18 countries. Diabet Med 1998;15:752-9.

36. Helgeson VS, Escobar O, Siminerio L, Becker D. Relation of stressful life events to metabolic control among adolescents with diabetes: 5-year longitudinal study. Health Psychol 2010;29:153-9.
37. Hoffman RP. Adolescent adherence in type 1 diabetes. Compr Ther 2002;28:128-33.

38. Law GU, Walsh J, Queralt V, Nouwen A. Adolescent and parent diabetes distress in type 1 diabetes: the role of self-efficacy, perceived consequences, family responsibility and adolescent-parent discrepancies. J Psychosom Res 2013;74: 334-9.

39. Hood KK, Huestis S, Maher A, Butler D, Volkening L, Laffel LM. Depressive symptoms in children and adolescents with type 1 diabetes: association with diabetes-specific characteristics. Diabetes Care 2006;29:1389-91.

40. Cousino MK, Hazen RA. Parenting stress among caregivers of children with chronic illness: a systematic review. J Pediatr Psychol 2013;38:809-28.

41. Powers SW, Byars KC, Mitchell MJ, Patton SR, Standiford DA, Dolan LM. Parent report of mealtime behavior and parenting stress in young children with type 1 diabetes and in healthy control subjects. Diabetes Care 2002;25:313-8.

42. Balfour L, White DR, Schiffrin A, Dougherty G, Dufresne J. Dietary disinhibition, perceived stress, and glucose control in young, type 1 diabetic women. Health Psychol 1993;12:33-8.

43. Fisher EB, Boothroyd RI, Elstad EA, Hays L, Henes A, Maslow GR, et al. Peer support of complex health behaviors in prevention and disease management with special reference to diabetes: systematic reviews. Clin Diabetes Endocrinol 2017;3:4.

Supplementary Material: The online version of this article offers supplementary material (https://doi.org/10.1515/jpem-2020-0339). 